REVIEW PAPER

Sri Lanka Journal of Medicine Vol. 25 No.2 2016

\title{
UNMET NEED FOR FAMILY PLANNING; GLOBAL AND NATIONAL TRENDS AND CHALLENGES
}

\author{
L.I. Malwenna, N.K.C. Gunarathna
}

National Institute of Health Sciences, Kalutara

Corresponding Author: Dr. L.I. Malwenna, Email: indrani.malwenna@gmail.com

Doi: http://dx.doi.org/10.4038/sljm.v25i2.22

\begin{abstract}
The unmet need for family planning refers to the percentage of all fecund women who are married or living in union and thus are presumed to be sexually active but not using any method of contraception, who either do not want to have any more children or want to postpone their next birth at least by two years or do not know when or if they want another child ${ }^{1}$.

Use of appropriate contraceptive method helps the user to avoid unplanned pregnancies, reducing the risk of induced abortion; the number one killer of women in the reproductive age in developing countries ${ }^{2}$. Due to its clandestine nature, most abortions in the developing world are unsafe, resulting in a series of complications, the most disastrous being maternal death. Worldwide, approximately 42 million pregnancies are voluntarily terminated, 22 within the national legal system and 20 outside it. The World Health Organization (WHO) estimates that a woman dies every 8 minutes due to complications of unsafe abortions ${ }^{3}$. Even though induced abortion is criminalized in Sri Lanka except to save the mother's life ${ }^{4}$, about 700 abortions are performed daily ${ }^{5}$, accounting for the second leading cause of maternal deaths in 2006, 2008 and $2010^{6}$. According to Demographic and Health Survey (DHS) 2006/7, 17.2\% of births in previous 5 years were unplanned or unwanted ${ }^{7}$. It has been revealed that, $73 \%$ among 365 abortion seekers had unmet need for family planning ${ }^{8}$. The economic burden of induced abortion is unbearable to the state and the total cost for management of complications of an abortion has been estimated to be 462 US \$, of which $79 \%$ is spent by government health expenditure ${ }^{9}$.
\end{abstract}

Key words: Unmet need, Family planning, reasons, consequences, impact

\section{Introduction}

The unmet need for Family Planning (FP) is defined as the percentage of all fecund women who are married or living in union and thus are presumed to be sexually active but not using any form of contraception, either do not want to have any more children or want to postpone their next birth for at least two more years or do not know when or if they want another child ${ }^{1}$. Unmet Need for modern methods includes all in the unmet need group and those who are using natural and traditional methods at the time of survey ${ }^{10}$

This unmet need may be either for limiting where a woman never wants a child; or for spacing where she wants a child only after 2 years or is not sure whether or when to have the next child ${ }^{11}$.

Thus, unmet need is a disconnection between the women's fertility preferences and what they do about them, indicating the failure to take necessary action to prevent conception. The concept of unmet need for FP is usually applied to married women but 
can also be applied to sexually active unmarried females and to men as well ${ }^{12,13}$.

\section{Evolution of the concept of unmet need for family planning}

The term was first described as "KAP-gap" reflecting the source of data because the gap between the need and the use of FP was first identified from surveys on Knowledge, Attitudes and Practices ${ }^{14}$.The term "unmet need" was first used by Stokes in $1977^{15}$.

According to the standard definition of unmet need, a woman is considered to have unmet need for family planning if she:

1. is married or in consensual union and in reproductive age (15-49 years)

2 . is fertile (infecund women are identified based on their ability of childbearing and contraceptive history)

3. wants to have no more children or to postpone child bearing by at least two years

4. do not know when or if they want another child

5. is using neither a traditional nor a modern method of contraception

6. is pregnant or in the post partum period and her latest pregnancy is mistimed or unwanted and has not used any contraceptive method before the conception ${ }^{16}$.

Unmet need for spacing is applied to non pregnant and non post partum women who are not using a FP method, who want more children but not for at least two or more years or are not certain whether they want to have another child or are not certain when they want to have another child or in case of pregnant females whose pregnancies were mistimed and had not used any form of contraception before the conception or in post partum women whose last births were mistimed and not used any form of contraception before the conception.
Unmet need for limiting is applied to women who do not want children at all but who are not using any form of contraception or pregnant females whose pregnancies were unwanted and who had not used any form of contraception before the conception or post partum women whose last births were unwanted and who had not used any form of contraception before the conception $^{16}$ (Figure 1).

The level of unmet need in a country is always changing, depending on the interplay of two factors, fertility desires and contraceptive use. Westoff and Bankole have observed it as a "moving target". It rises as more women want to control their fertility without contraceptive use, and it falls as more use contraception or change their preferences to have more children. Moreover, even where the proportion of women with unmet need is declining, the absolute number with unmet need may be growing because the population in the child bearing age is growing ${ }^{18}$.

\section{Worldwide estimations of unmet need}

Unmet need was first assessed using the World Fertility Survey, followed by Contraceptive Prevalence Surveys (CPS) conducted from 1978 to 1984 including only non pregnant and non postpartum women. The third was DHS using the standard definition including pregnant and postpartum women ${ }^{16}$.

Globally, unmet need has been estimated on four occasions using DHS data. The prevalence for unmet need in the developing world varied from $11 \%$ to $24 \%$ (average $17 \%$ ). It was around 24\% in Sub - Sahara Africa, $16 \%$ in North Africa, Middle East and Asia, $14 \%$ in Latin America and $11 \%$ in Central Asian Republics while in West Africa, having a range from 16 to $34 \%$. Overall, $80 \%$ of estimated global unmet need came from countries being surveyed ${ }^{19}$. 
However, contribution for unmet need by

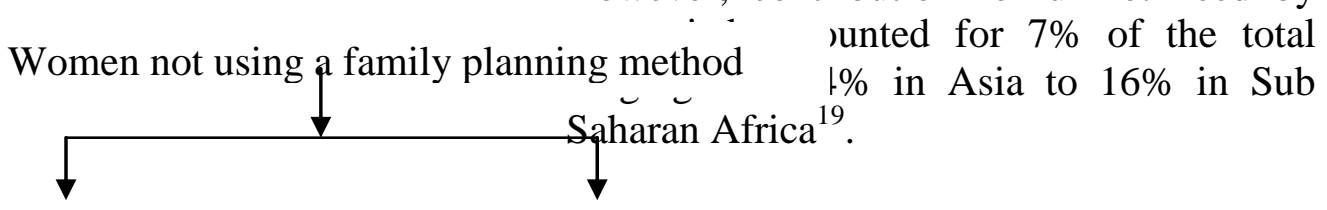

Pregnant or post-partum Non pregnant or amennorrheic

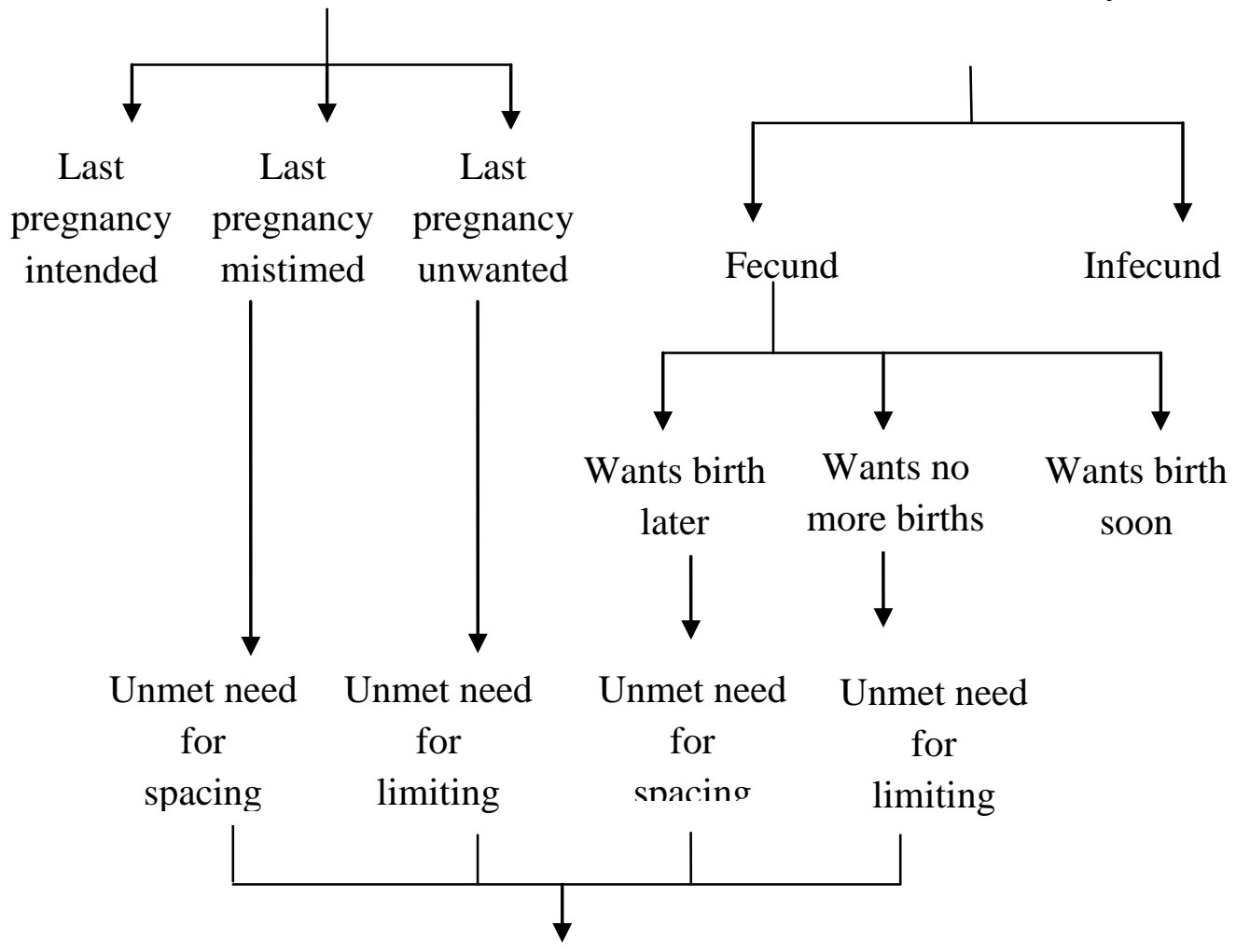

(after 6 weeks of delivery)

TOTAL UNMET NEED

Figure 1 - Arrangement of currently married women of reproductive age in various categories of pregnancy, fecundity and fertility intention, and total unmet need for $\mathrm{FP}^{17}$

Prevalence and proportion for limiting and spacing were similar across the Asian region except in Pakistan where the majority was for limiting. However, in Sub Saharan Africa, $65 \%$ was for spacing, where as in Latin America it was only $42 \%$. In spite of extensive family planning programmes, unmet need in Nepal remains high at $25 \%$ with $9.5 \%$ for spacing and $15.5 \%$ for limiting ${ }^{16}$.
According to the estimates by Westoff in 2006, among 58 developing countries included in the DHS program conducted since 1995, unmet need for FP is declining in many developing countries except Pakistan where it had increased from $31 \%$ to $33 \%$. There was consistent evidence of decline in total unmet need in 19 Asian, Near Eastern, and North African countries reviewed. Similar declines are seen in eight 
Latin American/Caribbean countries, except in Haiti and Nicaragua, which showed no change. In West Africa, no decline was apparent, in contrast to East and Southern Africa where declines are evident in about half of the countries ${ }^{2}$.

Unlike other regions of the world, in subSaharan Africa unmet need is mainly for spacing births. The primary exceptions are South Africa, Namibia, Malawi, Lesotho, and Kenya, where smaller family norms are more developed. However, it was over $20 \%$ in 31 of the 58 countries which are least developed. Moreover, even in countries experiencing declines, numerical increases in population growth can overcome the gains of reduced unmet need ${ }^{2}$.

According to the latest estimates by Westoff in 2006, the unmet need for modern methods averages $26 \%$ in the Asian countries, $32 \%$ in the Near East and North Africa, and $27 \%$ in Latin America and the Caribbean, 34\% in West Africa, and 31\% in East and Southern Africa. In the Philippines, where traditional methods comprise nearly one-third of all use, unmet need rises from 17 to $33 \%$ when confined to modern methods.
7 to $31 \%^{2}$. In order to assess the unmet need for FP in Europe, data was analyzed from Fertility and Family Surveys (FFS) conducted in recent years in selected ten states. It was found to be $3 \%$ in two European countries (Belgium and Spain) and below $10 \%$ in most. Unlike in developing countries, the contribution for the unmet need by pregnant individuals is relatively small probably due to lesser number of unwanted pregnancies continued in developed countries where abortions are legalized and rates are relatively high ${ }^{17}$. In USA, analysis of data in the National Survey of Family Growth revealed that unmet need was $11 \%$ while $49 \%$ of pregnancies were unintended and $54 \%$ of these ended up with induced abortions ${ }^{20}$

\section{Trends of unmet need in Sri Lanka}

In Sri Lanka, World Fertility Surveys (WFS) have been conducted in 1975, Contraceptive Survey (CPS) in 1982 and four DHSs in 1987, 1993, 2000 and 2006/7 by the Department of Census and Statistics (Table $1)$.

Table 1 - Levels of unmet need in relation to Contraceptive Prevalence Rate (CPR), Total Fertility Rate (TFR) and Wanted Fertility Rate (WFR) ${ }^{21}$

\begin{tabular}{llllll}
\hline Year & $\begin{array}{l}\text { Unmet need } \\
\text { for any } \\
\text { method }\end{array}$ & $\begin{array}{l}\text { Unmet need } \\
\text { for modern } \\
\text { methods }\end{array}$ & $\begin{array}{l}\text { Total } \\
\text { Fertility } \\
\text { Rate (TFR) }\end{array}$ & $\begin{array}{l}\text { Wanted } \\
\text { Fertility } \\
\text { Rate (WFR) }\end{array}$ & $\begin{array}{l}\text { Contraceptive } \\
\text { Prevalence } \\
\text { Rate (CPR) }\end{array}$ \\
\hline 1975 (WFS) & $*$ & $*$ & $3.4 \%$ & $* *$ & $34.4 \%$ \\
1982 (CPS) & $*$ & $*$ & $3.7 \%$ & $* *$ & $57.6 \%$ \\
1987 (DHS) & $22.7 \%$ & $56.9 \%$ & $2.8 \%$ & $2.4 \%$ & $61.7 \%$ \\
$1993(\mathrm{DHS})$ & $24.7 \%$ & $47.1 \%$ & $2.3 \%$ & $1.8 \%$ & $63 \%$ \\
$2000(\mathrm{DHS})$ & $18.2 \%$ & $38.7 \%$ & $1.9 \%$ & $1.8 \%$ & $71 \%$ \\
$2006 / 7$ (DHS) & $7.3 \%$ & $23.2 \%$ & $2.3 \%$ & $2.1 \%$ & $68 \%$ \\
\hline *Unmet need was not measured in these surveys ** WFR was not measured in these surveys
\end{tabular}

Another example is Moldova where withdrawal is common; when confined to modern methods, unmet need increases from
In 2007, unmet need for FP was found to be $12.6 \%$, with that of modern methods being $24 \%$ in Gampaha $\mathrm{MOH}$ area $^{22}$. In 2003, unmet need for modern methods in the 
Colombo Municipal Council area was found to be $24 \%{ }^{23}$. In a study conducted in the Kalutara District in 2010, unmet need for FP was found to be $9.4 \%$ with $1.5 \%$ for spacing and $7.9 \%$ for limiting, while that of modern methods was $18.7 \%$.

\section{Reasons for unmet need for family planning}

According to findings from comparable surveys and in-depth studies conducted worldwide, the reasons were;

- difficulties with access to and quality of FP supplies and services

- health concerns about contraceptives and adverse effects

- lack of information

- opposition from husbands, families, and communities

- little perceived risk of pregnancy ${ }^{25}$

According to the analysis of data in 1994 from 13 countries where DHS surveys have been conducted, Bongaarts \& Bruce have found that the principal reasons cited by women with unmet need in Sri Lanka included health concerns (19.3\%), husband's disapproval (14.6\%), infrequent sex (13.3\%), lack of knowledge (10.4\%), religious influence $(3.6 \%)$ and lack of access (3.2\%). Even in DHS 2006/7, health concerns were still cited $(11 \%)$ as the single most important non-biological reason for not using modern contraception, followed by husband's disapproval (3.9\%) and religious opposition (3\%) among married nonpregnant women who were not currently using a method of contraception and who reported being unhappy if they became pregnant too soon ${ }^{7}$.
In the study conducted in Gampaha $\mathrm{MOH}$ area, reasons for non use of modern contraceptives were fear of side effects (45.8\%), infrequent intercourse $(31.9 \%)$ and perceived low risk of pregnancy $(23.6 \%)$ where multiple responses have been allowed $^{22}$.

In the study conducted in District 1 Colombo Municipal Council, $71 \%$ of non users of modern methods gave community factors including lack of awareness, fear of side effects and husband's disapproval. Twenty nine percent were service factors including low postpartum coverage, side effects due to depo provera and intrauterine devise (IUD) and fear of IUD insertion procedure $^{23}$.

In Kalutara district, reasons identified for unmet need for FP were low perceived risk of pregnancy (36.2\%), fear of side effects $(30.5 \%)$ and less frequent sexual intercourse $(19 \%)^{24}$.

Globally, identified contributing factors for unmet need for FP are low mean age at marriage, low female education and gender discrimination $^{18}$. In Sri Lanka, there had been increased association between unmet need and low levels of education until 1993, which has disappeared thereafter in DHS 2000 and 2006/7. There was no statistical relationship with sector of residence or age of the participants in any of the DHSS. Although rural areas had the lowest unmet need $(6.8 \%)$ in comparison to urban $(9.5 \%)$ and estate (11.1\%) sectors in DHS 20066/7, this difference was not statistically significant $^{21}$.

The study conducted in Gampaha district revealed statistically significant increased risk of unmet need for FP in relation to educational status of below primary education, reduced level of sexual contact, intention to attempt for an induced abortion 
if conceived, unawareness of the existence of a law on induced abortion and unawareness of the risks of induced abortions $^{22}$. In the Kalutara district study, a significantly increased risk of unmet need was found to be associated with being older than 35 years, having an education below primary level and being unemployed, having sex less frequently than once a week, desire of not having any more children, not expecting to use a modern FP method in future and not having counseling in $\mathrm{FP}^{24}$.

\section{Consequences of unmet need for FP}

The only sequela of unmet need is unintended and thus unwanted pregnancy, with its disastrous consequences leading to induced abortions. Induced abortions are mostly unsafe in developing countries, subjecting women to unsafe procedures with high risk of mortality and morbidity like chronic pelvic inflammatory disease, infertility and associated ectopic pregnancies, premature deliveries with added weight of psychological distress. Continuation of such pregnancies bears the risks of adverse pregnancy outcomes (low birth weight, small for gestational age and preterm birth) resulting postnatal morbidity and infant deaths ${ }^{25}$.

In 1987, an estimated 26-31 million legal and 10-22 million clandestine abortions were performed worldwide, with the rate of illegal abortions being 35 per 1000 women in the age group of 15-44 years. The same rate continued until 1995 and decreased to 29 by 2008. But the rate of unsafe abortions increased from $44 \%$ in 1995 to $49 \%$ in 2008 because the contribution towards global abortions by developing countries increased from $78 \%$ in 1995 to $86 \%$ in $2008^{27}$. In those countries, safe abortion practices are not available although abortion is legalized on broad grounds.

\section{Impact of Meeting Unmet Need}

Starting a modern family planning method by each woman in the developing world with unmet need will prevent 52 million unintended pregnancies annually; thus preventing 22 million abortions; of which $60 \%$ occur now in the developing world. Providing these services and supplies would cost an additional $\$ 3.9$ billion per year, but the savings would ultimately dwarf that figure. As seen in a typical low-fertility Latin American country, every dollar spent on family planning saves $\$ 12$ in health and education costs from averted pregnancies, abortions, births and complications ${ }^{28}$.

Reducing unmet need by accepting FP would eventually increase the birth intervals of siblings. It has been revealed that children born having spacing more than two years were 1.5 times more likely to survive the first week of life, 2.2 times more likely to survive the first 30 days of life, 2.3 times more likely to survive the first year of life and 2.4 times more likely to survive up to age five. Further, compared to women who give birth after a 9-11 months interval, women who have their babies after a 27-32 months interval are 1.3 times more likely to avoid anemia, 1.7 times more likely to avoid third trimester bleeding and 2.5 times more likely to survive child birth ${ }^{11}$.

Thus, it is evident that having strict abortion law is not supportive of reducing unsafe abortions and related consequences, but the only way is to reduce unmet need for FP and the incidence of unplanned pregnancies is by using effective FP methods. 


\section{References}

1. United Nations 2009, Department of Economic and Social Affairs, Population Division World Contraceptive Use 2009, Viewed on $13^{\text {th }}$ February 2010, $\mathrm{POP} / \mathrm{DB} / \mathrm{CP} / \mathrm{Rev} 2009$.

2. Westoff C.F. 'New Estimates of Unmet Need and the Demand for Family planning', DHS Comparative Reports 2006 No. 14, Macro International Inc, Calverton, Maryland, USA:1-8.

3. WHO, Unsafe Abortion. Global and regional estimates of unsafe abortion and associated mortality in 2003, $5^{\text {th }}$ Edn, pp.112.

4. The Ceylon Penal Code

5. Abeykoon A.T.P.L, Estimates of abortion rates in Sri Lanka using Bongaarets Model of Proximate Determinants of Fertility: 4-5.

6. Family Health Bureau. National Maternal Mortality Reviews - 2011

7. Ministry of Plan Implementation. Demographic and Health Survey 2006/07: Department of Census and Statistics, Ministry of Plan Implementation, Colombo, Sri Lanka;2008:51-94.

8. Rajapaksha L.C. 2002, 'Estimates of induced abortion in Urban and Rural Sri Lanka', Journal of the College of Community Physicians of Sri Lanka 2002; 7: 10-16

9. Thalagala N.I. Process, determinants and impact of abortions in Sri Lanka, Family Planning Association Sri Lanka. /IPPF (SEARO) 2010:1-10.

10. Degraff D.S., De Silva V. A new perspective on the definition and measure of unmet need for contraception. International Family Planning Perspectives 1996; 22 (4):140-147. Doi: 10.2307/2950811

11. Westoff C.F., Ochoa L.H. The demand for family planning 1996. Institute for Resource development, /Macro International: Colombia, Maryland.

12. Becker S. 'Measuring Unmet Need, Wives, Husbands or Couples', International Family Planning Perspectives 1999; 25 (4):172180. Doi: $10.2307 / 2991881$

13. Ngom P. Men's Unmet Need for Family Planning: Implications for AfricanFertility Transitions. Studies in Family Planning 1997;28 (3):192-202. Doi: 10.2307/2137887

14. Casterline J.B., Sinding A. Unmet need for family planning in developing countries and implications for population policy., Population Developing Review 2000;26 (4): 691-723.

Doi:10.1111/j.17284457.2000.00691.x

15. Stokes B. Filling family planning gaps', Population Reports.1977 Series J, No.20, John Hopkins School of Public Health, Population Information Programme, Baltimore:10-21.

16. Westoff C.F. The potential demand for family planning: A new measure of unmet need and estimates for five Latin American countries. International Family Planning Perspectives, 1988;14:2:45-53.

Doi: $10.2307 / 2947679$

17. Klijzing E. Are there unmet family planning need in Europe. Family Planning Perspectives 2000;32 (2): 74-81, 88. Doi $10.2307 / 2648215$

18. Westoff C.F, Bankole A. Unmet need, DHS Comparative Studies: 1990-1994, Calverton, Macro International, Maryland, viewed on 10.11.2007, < $\quad$ http://www.jhuccp.org/ popline/popbid/j43.shtml\#237>.

19. Ross J., Winfery, W.L. Unmet need in the developing world and former Soviet Union. An updated estimate', International family planning perspectives 2002;28(3):138-143. Doi: $10.2307 / 3088256$

20. Henshaw, SK 1998, 'Unintended Pregnancy in the United States', International Family 
Planning Perspectives 1998;30(1):24-29 and 46.

21. Family Health Bureau. Fertility Changes and its Implications on Maternal and Child health, Colombo, Sri Lanka 2009.

22. Liyanapathirana, A. 'Unmet need for family planning: Extent and factors associated among married women of reproductive age in $\mathrm{MOH}$ area Gampaha', Community Medicine Msc Dissertation, PGIM, University of Colombo, Sri Lanka 2007.

23. Lianarachchi K.D. Surveillance and factors associated with non use of modern family planning methods among married women of reproductive age group in District 1 of Colombo CMC', Community Medicine MSc Dissertation, PGIM, University of Colombo, Sri Lanka 2003: 57-60.

24. Malwenna L.I. Prevalence and correlations of unmet need for family planning and effectiveness of community based intervention in reducing unmet need for modern methods among women ever married in reproductive age in the Kalutara District. Community Medicine MD Dissertation, PGIM, University of Colombo, Sri Lanka 2010:57-60.

25. Bongaarts J., Bruce J. The causes of unmet need for contraception and the social content of services', Studies in Family Planning 1996;26(2):57-75. Doi: 10.2307/2137932

26. Henshow S. K., Singh S., Haas, T. The Incidence of Abortion Worldwide', International Family Planning Perspectives 1999;25: S30-S38. Doi: 10.2307/2991869

27. Sedgh G., Singh S., Henshaw S.K, Bankole A. Induced abortion: incidence and trends worldwide from 1995 to 2008. The Lancet 2012;379(9816):625632. Doi:10.1016/S01406736(11)61786-8

28. Sonfield, A 2006, 'Working to eliminate the World's Unmet Need for Contraception', Guttmacher Policy Review, viewed 10
December 2007. Available at https://www.guttmacher.org/gpr/2006/03/wo rking-eliminate-worlds-unmet-needcontraception 